\title{
Evaluating Interior Spruce Seed Deployment with GIS-Based Modeling Using British Columbia's Prince George Seed Planning Zone as a Model
}

\author{
By C. Ding( ${ }^{1)}$, L. McAuley ${ }^{2)}$, M. J. Meitner ${ }^{3)}$ and Y. A. El-Kassaby ${ }^{3), 4), *}$
}

(Received $5^{\text {th }}$ June 2012)

\begin{abstract}
The maintenance, protection, and conservation of forest genetic resources for economic, ecological and social benefits are daunting tasks. Understanding how reforestation materials are spatially and temporally deployed across the landscape is an integral component of forest genetic resources management. To improve the current understanding of how reforestation materials are deployed in British Columbia (BC), we developed a geographical information systems (GIS) method to track seed deployment across silviculture openings. Generally, reforestation materials can originate from either natural stand (wild seed collections) or orchards' seed sources (improved seed); the latter are produced within the framework of specific tree improvement program designed for a particular species within a well-defined seed deployment area, commonly known as Seed Planning Zone (SPZ). In this paper, we present a GIS-based method for evaluating seed deployment patterns for interior spruce (Picea glauca and Picea engelmannii and their natural hybrids) within the Prince George SPZ. The evaluation period (1970-2004) is associated with wild stands and improved seed availability and the dynamic of each seed source proportionate contribution followed three distinct phases; namely, developing (1970-1987), immature (1988-1994), and mature (1995-2004) with a progressive increase of orchards' seed use over time. The developed method is scalable across SPZs of the same species or multiple species, thus providing the means to: 1) temporally and spatially monitor improved and natural stands seed deployment over the landscape; and 2) identify areas of concerns where a particular seed source is over-represented which might pose an increased genetic vulnerability. The present study revealed that the current interior spruce orchard's seed use within the Prince George SPZ is expected to exceed the provincial goal of performance target of $75 \%$ by 2014 . Additionally, areas of excessive use of one seed orchard seed were identified.
\end{abstract}

Key words: Geographical information system; Interior spruce; Seed Planning Zone; Wild stands and seed orchard seed; Deployment in time and space.

\footnotetext{
$\left.{ }^{1}\right)$ Department of Renewable Resources, University of Alberta, Edmonton, AB, Canada T6G 2H1.

$\left.{ }^{2}\right)$ Tree Improvement Branch, Ministry of Forest, Lands and Natural Resource Operations, PO Box 9518 Stn Prov Govt, Victoria, BC, Canada V8W 9C2.

3) Department of Forest Resources Management, University of British Columbia, Vancouver, BC, Canada V6T 1Z4.

4) Department of Forest Sciences, University of British Columbia, Vancouver, BC, Canada V6T 1Z4.

*) Corresponding author: YousRY A. El-Kassaby. Phone: (604) 822-1821, Fax: (604) 822-9102. E-Mail: y.el-kassaby@ubc.ca
}

\section{Introduction}

The forests in British Columbia (BC) are in the midst of dramatic changes as a result of climate change (MoRIN et al., 2007) and its obvious mountain pine beetle epidemic by-product (KURZ et al., 2008). To ensure forest management practices can be adapted to address these changes, a better understanding is necessary of how the seed used in reforestation has been spatially and temporally deployed and distributed across the landscape. In BC, a comprehensive Gene Resource Management (GRM) program is carried out to ensure the protection, conservation, and maintenance of the publically-owned provincial forest tree genetic resources and to safeguard future options and benefits for British Columbians (Tree Improvement BrANCH, 2007). However, given the multiple spatio-temporal scales of operations, forest and natural resource planners, practitioners, geneticists, seed orchardists, and tree breeders lack sufficient information to carry out GRM effectively at the stand, forest, and landscape level. To address this knowledge gap, we present an evaluation of historical seed use practices using the provincial silviculture information collected since the 1970's and suggest geographic information systems (GIS) analysis that may prove useful in the development of a decision-support system to aid GRM managers and decision-makers.

In BC, GRM comprises a suite of activities focused on maintaining and enhancing forest productivity, health, and genetic diversity across the managed forest land base. GRM goals and objectives assist the conservation, management, monitoring, and assessment of BC's forest tree genetic resources, including support for the provincial tree improvement and tree breeding programs, allowing for the sustainable management of $\mathrm{BC}$ forests (TREe ImPRovement BRANCH, 2009). GRM is comprised of three key elements: value (genetic gain), conservation (species and genetic diversity), and resilience (adaptation) (Forest Genetic Council of BRitish Columbia, 2009). Value refers to increasing the timber and nontimber economic value of planted forests, which is realized through regeneration with seed/seedlings from known level of heritable improvement of targeted or desired traits resulting from tree breeding programs. Conservation refers to the maintenance of natural levels of genetic diversity for tree species indigenous to $\mathrm{BC}$, including in situ and ex situ approaches. Resilience refers to the adaptation of forest genetic resources, including reforestation stock, for the purposes of matching genotypes of trees to planted sites (environments) and maintaining natural genetic diversity in the planted populations of trees. All this is accomplished through 
the application of sound forest genetics, genecology, and conservation practices (FOREST GENETIC COUNCIL OF BRITISH COLUMBIA, 2009).

GRM is important for two major reasons. First, it provides a framework for operational guidelines pertaining to forest regeneration, silviculture, seed use, conservation, and tree improvement activities such as seed planning, seed registration, and collection, seed orchard production, selection and use, seed transfer (movement of seed), and deployment in order to meet annual operational reforestation needs. Second, it fosters a solid foundation for providing continued evolution, improvement, and adaptation of public forests. Thus, GRM plays a critical role in assisting natural resource stewards and forest managers in achieving the goal of sustainable forest management.

Assessing the outcomes of GRM is a difficult task often associated with the character and environment of forests. Tree species have longevity and grow in complex environmental conditions (LEDIG, 1986) and exist in large management areas characterized by substantial intrusive manipulation through naturally occurring, and oftentimes catastrophic, abiotic and biotic disturbance events, as well as human-directed activities such as harvesting and silviculture. Meanwhile, the necessary capacity of GRM spatial data analysis is lacking compared to advances in genetics research and tree improvement practices (LEFÈVRE, 2004). Thus, it is very difficult to assess the outcomes of GRM policies and practices in order to better understand: 1) the impact of policies that guide the selection and use of genetically improved stock for reforestation, and 2) the effectiveness of policies and program management goals in maintaining forest productivity, health, resilience, and adaptation.

Geographical information systems (GIS) are powerful tools to manage and analyze such complex spatially-referenced data and have been widely applied in ecology (MAllawaARACHCHI et al., 1996; Powell et al., 2005; TSIHRINTZIS et al., 1996) and forest genetics (YING and YANCHUK, 2006). GIS and spatial statistics were used to develop seed transfer guidelines and seed zones for red alder (Alnus rubra) (HAMANN et al., 2000), to catalogue the status of in situ genetic conservation for eleven commercial tree species indigenous to BC (HAMANN et al., 2004), and to construct the eco-geographic zones for the in situ conservation of Douglas-fir (Pseudotsuga menziesii (Mirb.) Franco) (HAMANN et al., 2005). Other researchers have used GIS to support the conservation of biodiversity and forest genetic resources through the implementation of gap analysis (JENNINGS, 2000; LIPOW et al., 2004; SARA et al., 2004) as well as assessing logging disturbances (PEARSON, 2010). In the context of GRM, GIS can also be applied to summarize and visualize the impacts of seed deployment at the stand and landscape level through the use of coarse and fine filters based on geographic distribution, genetic sources, quantity, and quality. However, the vast majority of studies have traditionally focused on conservation programs related to the management of endangered species or wild tree species and less effort has been placed on com- mercially important species such as those managed in intensive plantations.

Of particular significance is forest management of interior spruce complex (Sx) as it's one of the top commercial tree species in $\mathrm{BC}$, with an average annual planting of 50 to 80 million seedlings per year (BRITISH COlumbia Ministry of Forests, LANDS AND NATURAL RESOURCE OpERATIONS, 2011). Interior spruce (Sx) is the common and/or operational name for the naturally occurring white-Engelmann spruce hybrid complex (Picea glauca and Picea engelmannii). The white and Engelmann spruce are characterized by substantial ranges overlap and lack of reproductive barriers, thus hybridization is common with hybrid swarms ranging from being pure to one species to various levels of interspecific hybridization and backcrosses (NIENSTAEDT and ZASADA, 1990). The BC interior spruce tree improvement program is well-established (MORGENSTERN and WANG, 2001), resulting in the development of several seed orchards in the early 1980's (WoODS, 2006, 2007; BRITISH Columbia Ministry of Forests, Lands and Natural Resource Operations, 2011), each is designed to serve a specific Seed Planning Zone (SPZ). However, historical activities pertaining to forest management of interior spruce, including seed use practices, have not been wellinvestigated spatially (YING and YANCHUK, 2006).

The main objectives of our study were to 1 ) create a GIS-based method for evaluating the spatio-temporal trends of historical reforestation practices, 2) provide an overview of impacts resulting from seed use practices based on the spatial patterns and genetic landscape of seed deployment frequency, and 3) analyze the stand level genetic composition. In this study, we used the interior spruce Prince George Seed Planning Zone as an example which can be scaled to accommodate multiple SPZs for the same species or across species.

\section{Materials and Methods}

\section{Study area}

The Prince George (PG) Seed Planning Zone (SPZ), located in the central-interior region of $\mathrm{BC}$, was selected as our primary study area. The spatial scale of GRM in $\mathrm{BC}$ is both multi-layered and hierarchical, including both stand and landscape levels. The stand level comprises silviculture openings that capture the information of reforestation, seed selection, use, and deployment. And the landscape level includes climatic, ecological, and genetic information that is described by the biogeoclimatic ecosystem classification (BEC) (POJAR et al., 1987; see below) and Seed Planning Zone-Unit (SPZSPU) classification systems. Seed Planning Zones $(\mathrm{SPZs})$ are the spatial representation of genetic variation and ecological conditions for the reforested tree species based on provenance trial series (BRITISH Columbia Ministry of Forests AND RANGe, 2009a; MeIdinger et al., 2005; Morgenstern, 1996; Ying and YANCHUK, 2006). Two sets of SPZs have been delineated for BC: natural stand SPZs and orchard SPZs. Orchard $\mathrm{SPZ}_{\mathrm{s}}$ are species-specific, with a unique set of zones/units described for eleven commercial tree species (HAMANN et al., 2004). Seed Planning Units (SPUs) are 
areas contained within orchard SPZs that are further sub-divided by elevation; typically each SPZ has a low and a high elevation SPUs. The breeding population of the Prince George SPZ, the main study area, also extends to two transition zones, commonly referred to as "overlap zones": 1) the Prince George-Nelson (PGN) and 2) the Bulkley Valley-Prince George (BVP).

Silvicuture openings are the spatial unit for reforestation activities captured at the operational level, including silviculture treatments such as planting or areas left open after spacing. The spatial data for silviculture openings was retrieved from GeoBC's, Geographic Warehouse, referred to as the Land Resource Data Warehouse (LRDW) (GEOBC, 2011), and the associated attribute information was downloaded from the Reporting Silviculure Updates Tracking System (RESULTS) (British Columbia Ministry of Forests, LANDS AND NATURAL Resource Operations, 2011).

The BEC system was created to develop a "permanent," land-based, ecological classification tool that organizes the knowledge of the natural environment as a basis for managing natural resources (POJAR et al., 1987). BEC classification is comprised of three levels: vegetation, zonal, and site (BRITISH COLUMBIA MINISTRY OF Forests AND RANGE, 2009b). Climate, soil moisture, and nutrient regimes (edatopic grid), succession climax, terrestrial, and vegetation factors form the basic elements for determination of BEC zones (POJAR et al., 1987). There are ten BEC zones that fall within the Prince George seed orchard SPZ, where five zones are large enough in area to be visualized and mapped (Figure 1). The five major BEC zones are: ESSF (Engelmann Spruce - Subalpine Fir), ICH (Interior Cedar - Hemlock), IDF (Interior Douglas-fir), SBPS (Sub-Boreal Pine - Spruce), SBS (Sub-Boreal Spruce). The black polygons in Figure 1 represent the spatial distribution of the silvicultural openings in the Seed Planning Zone. These BEC zones represented the climatic, edaphic, and ecological trends of natural populations of interior spruce, which are different from the SPZ system but indicates the natural range of species distribution (YING and YANCHUK, 2006).

Our primary reporting period followed the initiation of the interior spruce seed orchard program, covering 1995 to 2004 for the Prince George (Orchard) zone. The seed deployment from 1970 to 1995 in the interior of BC was also reported as a background reference. In respect to the genetic sources of seed stock, four categories were reported: orchard seeds ("A"), wild seeds from superior provenances ("B+"), wild seeds ("B"), and other natural seed sources without a label ("N": unavailable genetic source information) (WoODS, 2007; BRITISH ColumBIA Mibnistry of Forests AND RANGe, 2007a).

\section{Data preparation}

We used ArcGIS 9.3 for GIS modeling and spatial analyses in this study (ESRI, 2011). The quality and integrity of input spatial and aspatial data was examined prior to modeling. For the spatial data, they comprised the silviculture opening polygons, the SPZ and unit polygons as well as the BEC zone coverage. The

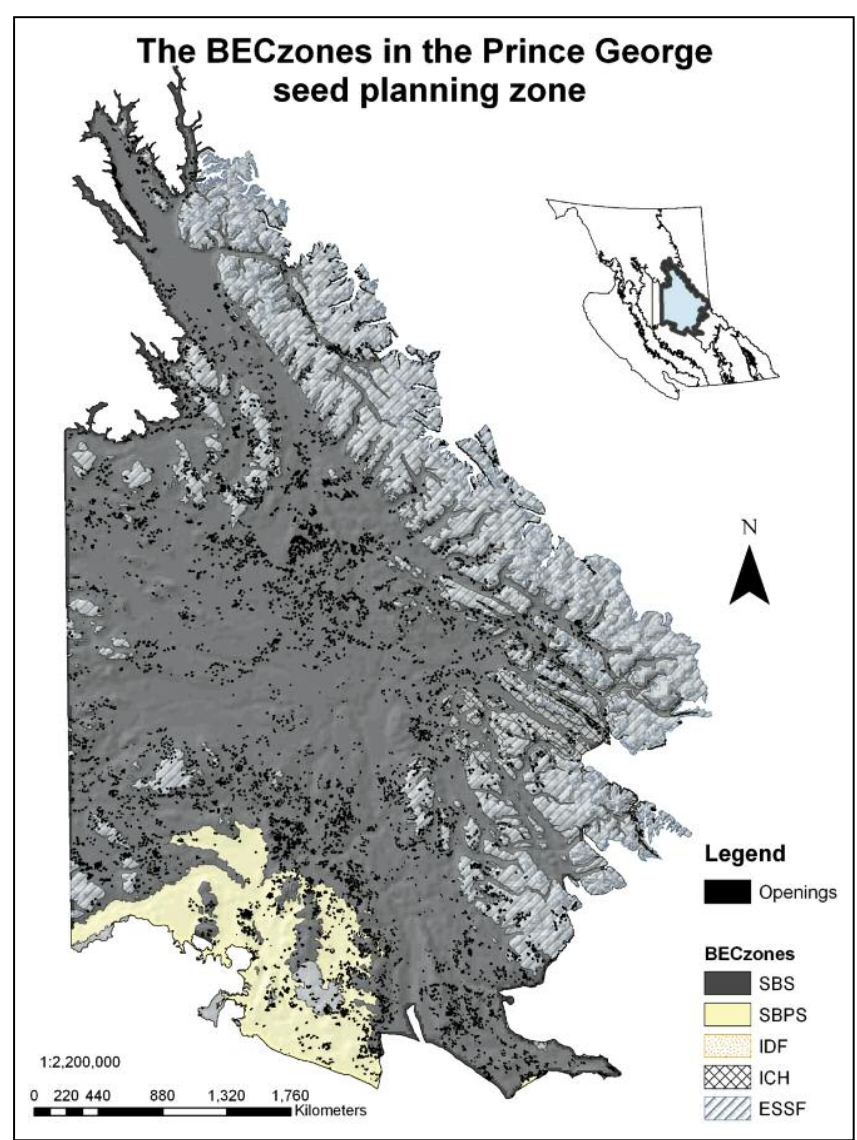

Figure 1. - Biogeoclimatic classification (BEC) zones contained within the Prince George Seed Planning Zone (SBS; SubBoreal Spruce; SBPS: Sub-boreal Pine Spruce; ICH: Interior Cedar-Hemlock; IDF: Interior Douglas-Fir; ESSF: Englemann Spruce-Subalpine Fir) (POJAR et al., 1987).

aspatial data, silviculture tables and natural regeneration records were extracted from the attribute data source from the RESULTS.

\section{Model description}

The spatial modeling was constructed with ArcGIS ModelBuilder (ESRI, 2011). The spatial openings and the attribute data were combined to summarize the silviculture and natural regeneration changes. Map representations of plantation distribution were generated with the modeling outputs by year and the seed source. Three separate models were created: the SPZ model, the SPU model, and the BEC zone model. The SPZ model clipped the opening polygons by the Prince George zone boundary to extract the main study area. It reported historical forest cover change at the SPZ level: Bulkley Valley/Prince George zone (BVP), Prince George/Nelson (PGN), and PG. The SPU model summarized spatial features of the two SPUs (Prince George High and Prince George Low); while the BEC zone model was used to describe the seed deployment differences within the BEC zone system overlayed with the SPU. For all models, frequency analysis was used to descriptively analyze the silviculture processes by forest cover types (e.g., the planted and natural regeneration), years, genetic classes (e.g., "A", "B" and "B+"), and seed used from seed 
orchard \#214 which delivered the highest genetic gain among all the 13 orchards within the Prince George zone.

The ArcGIS tool-Kernel density analysis was applied for mapping the hotspot of plantation events and the deployment of specific seed sources spatially (SILVERMAN, 1986). Thus we interpolated a density surface based on the occurrence of seed deployment with point data of the openings. By using ArcGIS tool-Hotspot Analysis, the Getis-Ord Gi* Z score (MITCHELL, 2005) and $P$-values were calculated to reveal the hotspot of orchard \#214 seed use in terms of occurrence and planted amount.

\section{Results}

Incremental seed deployment in $B C$

The tree improvement programs in BC changed the genetic composition of forest, for example, from 1970 to
2004 the total number of interior spruce trees planted has increased by 1.56 billion covering 1.19 million hectare (ha). The history of the interior spruce seed deployment can be characterized by three stages: 1) developing (1970-1987), 2) immature (1988-1994), and 3) mature (1995-2004) (Figure 2). During the developing stage, the cumulative increase of the plantation rose to 311,031 ha, mainly from natural stands with less than $0.1 \%$ made up from selected superior provenances ("B+" class). During the immature stage, 336,775 ha were reforested representing a dramatic increase of seed deployment with orchard seed increasing from $0.13 \%$ to $19.67 \%$ annually of the total deployment. During the mature stage, the cumulative reforestation area reached 547,926 ha with a substantial increase of orchard seed reaching $43.8 \%$ in 2004 of the total deployment, notwithstanding the reforestation slow-down. The plantation area rose to a maximum in 1996 and dropped to 46,095 ha in 2004; however, the orchard seed ratio rose steadily in the meantime. The previously dominant "B"

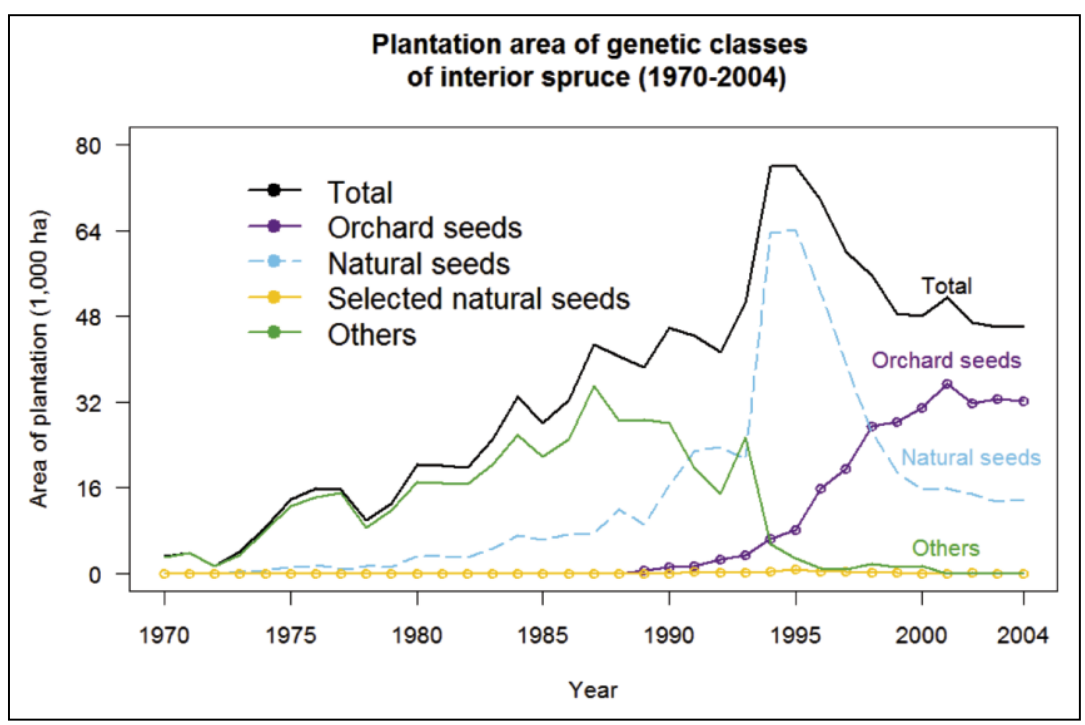

Figure 2. - Plantation area planted with interior spruce classified by genetic class (1970-2004) in the province of British Columbia.

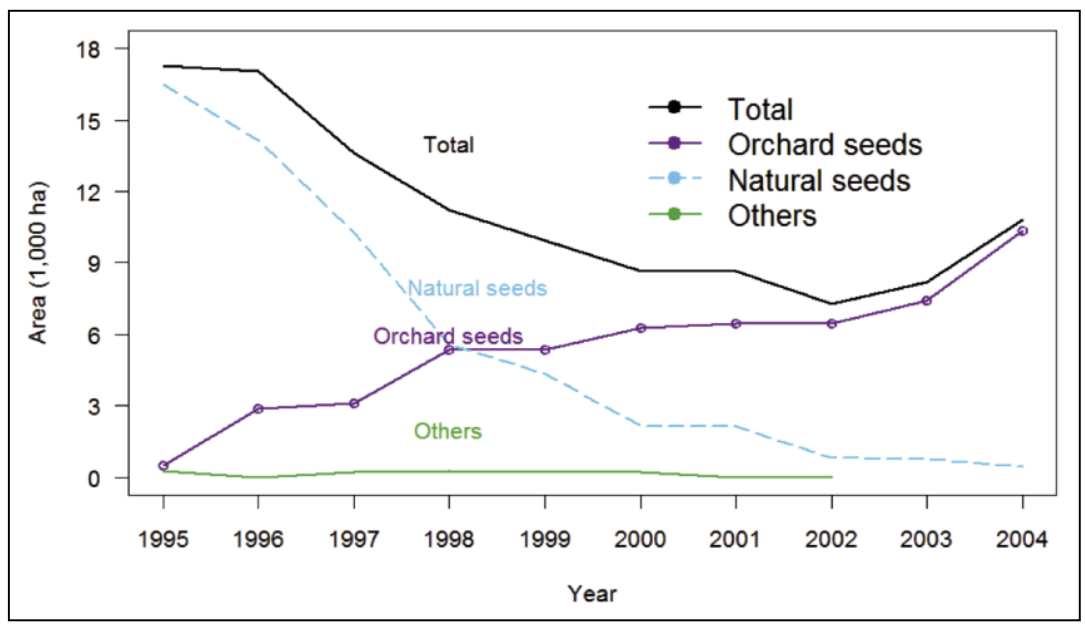

Figure 3. - Plantation area planted with interior spruce classified by genetic class (1995-2004) in the Prince George Seed Planning Zone. 
class was eventually replaced by orchard seed ("A"). The "N" class was not a large proportion of the total plantation after 1995, although it made up more than a half of the total stems during the slow increase stage.

This overview of the plantation activity for the interior spruce over the 34-year period demonstrated an ascending trend of the forests' genetic composition in $\mathrm{BC}$, including the Prince George zone. The reported area of natural regeneration represented only $5.6 \%$ of forest recovery in the $\mathrm{BC}$ interior, which was much less than the plantation areas. Conversely, when all silviculture records were included, the ratio of the plantation remained above $90 \%$ after the 1970 s.

\section{Transition Seed Planning Zones}

Although the Prince George zone was our main study area, the two adjacent zones PGN and BVP were also investigated for two reasons; 1) interior spruce (Sx) is also planted in both PGN and BVP zones and 2) the Prince George zone was the main source of interior spruce seed for PGN and BVP zones. The Prince George, PGN, and BVP zones, all had much less plantation area before 1988 than they did after 1988. As well, the nonselected seed source ("B" class and "N") took $84 \%$ of total plantation area prior to 1988 . The "B" class seeds, which represented $50 \%$ of the total seed deployed, had a maximum in 1995, and they were more intensively dispersed in PGN and BVP zones. For orchard seed deployment, the Prince George zone was the leading among these three zones with $90.6 \%$ of seed use specifically after 1995 while the remaining $9.4 \%$ were deployed in PGN and BVP zones.

\section{The Prince George Seed Planning Zone}

In the Prince George zone, over a ten year period (1995-2004), 48.1\% of the silviculture activities used orchard seeds. The orchard seeds increased consistently when compared with other classes and peaked at $96 \%$ in 2004, while "B" class showed a reverse trend (Figure 3). Regarding orchard seed use, orchard \#214 was the dominant source for seed for this area. For example, in 2004 seed orchard \#214 provided $90.7 \%$ of total seed deployment. The main reason for this extremely high concentration of seed use from one seed orchard was its higher genetic gain (measure of productivity) and larger effective population (measure of genetic diversity) (note this orchard has parental population size of 34; FOREST Genetic Council of British Columbia, 2009). This orchard produced 17 seedlots, of which two (\#60269 and \#60118) had the largest plantation area (Figure 4c). In general, this orchard's top 10 seedlots provided $90 \%$ of the seed stock, reaching $35.62 \%$ of the total reforestation activities and $41.1 \%$ of the plantation area.

\section{Seed Planning Units within the Prince George Seed Planning Zone}

BEC zones indicated the regional distribution of natural forest tree species (MEIDINGER et al., 2005), which constrained the deployment range of the selected seeds. Interior spruce in this region covered alpine tundra,

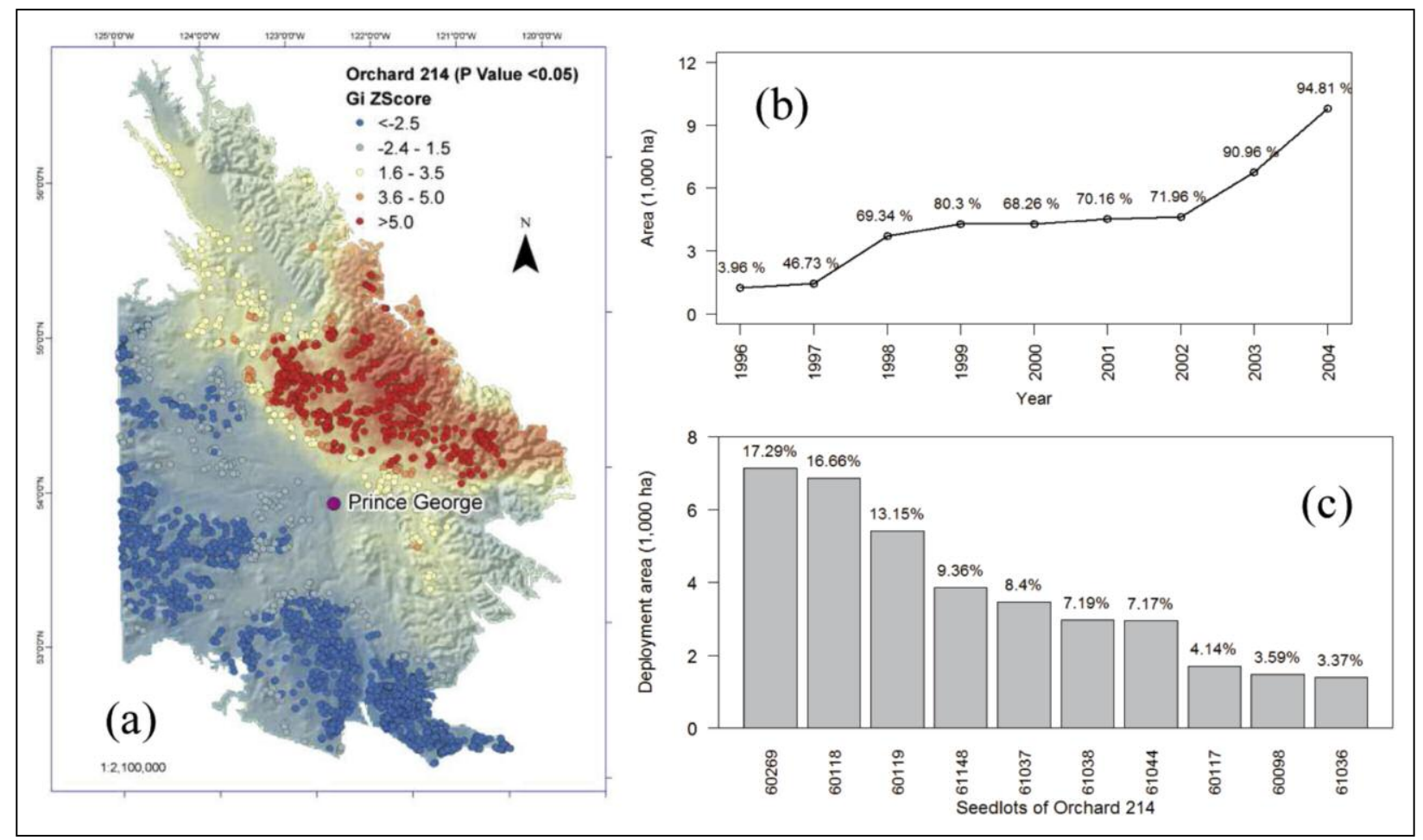

Figure 4. - Pattern of orchard 214 seed deployment in the Prince George Seed Planning Zone (1995-2004). (a) Hotspot analysis map of interior spruce reforestation (P-values $<0.05)$. The circle in the middle area is the location of Prince George city. Red circles indicate the hotspots while blue ones indicate the cold spots. (b) Area treated by year (1996-2004), and the percentage ratio is the annual deployment area of Orchard 214 versus the area of all seed orchards ("A") in this zone. (c) The top ten seedlots (1996-2004) in orchard \#214. The percentage shows the ratio of use area of each seedlot within Orchard \#214. 
subalpine, and montane boreal regions (e.g., Engelmann Spruce- Subalpine Fir (ESSF), Sub-Boreal Spruce (SBS), and Sub-Boreal Pine - Spruce zones (SBPS)); however, 94\% of plantation activities in the Prince George SPZ (seed planning zone) took place in SBS (73.07\%) and ESSF (21.33\%). As more orchards' seed were deployed in

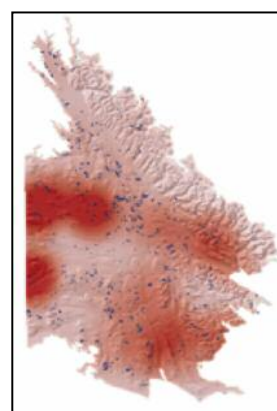

1995

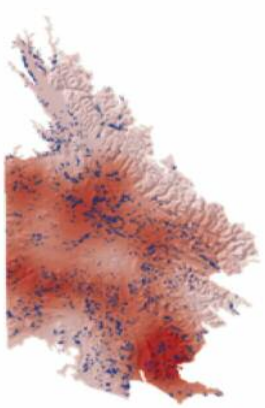

1998

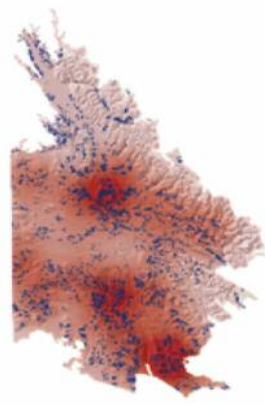

2001

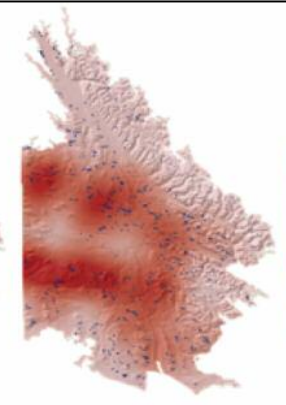

1996

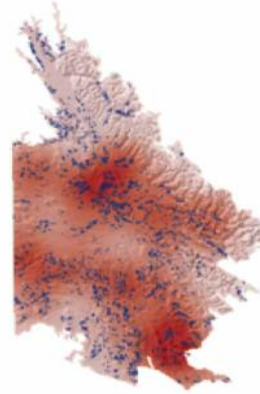

1999

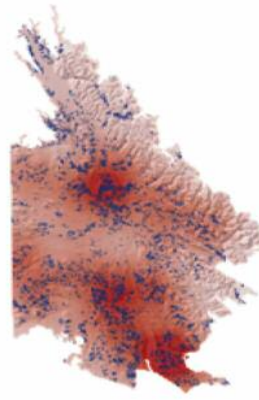

2002

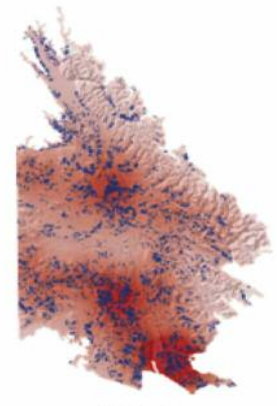

2004

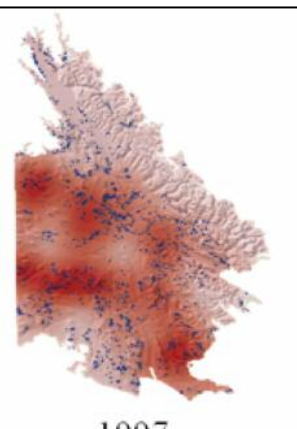

1997

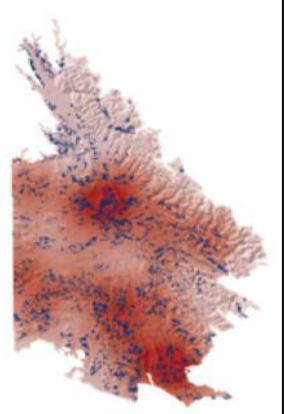

2000

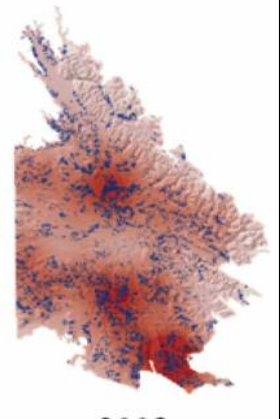

2003
No plantation

Figure 5. - Map series showing the temporal changes of opening distributions with orchard seeds ("A") deployed (1995-2004). Note: The red area has a dense plantation of the orchard seeds ("A"). The grey area shows few occurrences of plantation of "A" class. The small blue polygons indicate the actual locations of these openings.
SBS and ESSF, this rate continued to rise. SPUs (seed planning units) indicated the topographical variation between different seed sources, where the SPU Prince George-low was one target area for plantation as its elevation range overlaps with the SBS zone. In the SPU Prince George-low, orchard's seed were intensively used, especially that of orchard \#214. Generally, the total area of this orchard's seed increased in both Prince George SPUs (low and high) (Woods, 2007).

\section{Map representations of hotspots}

Map representations allow the visualization and monitoring the spatial distribution of plantation over time. This was conducted for the Prince George zone from 1995 to 2004. The map representation consisted of a hotspot analysis to identify plantations' occurrence of orchard \#214, as well as the kernel density of reforested openings over time. Figure 5 depicts the kernel density of openings distribution in the reforestation. There were three dense plantation clusters after ten-year GRM practices: one was in the north and two in the south of Prince George city. Each cluster indicated a region where orchard seeds ("A") were more frequently deployed. Figure 4 provides an overview of hotspots where different amounts of orchard \#214 seeds were deployed based on the Getis-Ord statistics: A higher Gi* score (e.g., >5.0) showed that the openings were statistically significantly clustered, while the blue openings with low scores (e.g., <-2.5) were sparsely distributed (ANSELIN, 1995). The red dots indicated a hotspot in the northeast, where openings with more stock of orchard \#214 seeds occurred while the blue dots indicated the cold spot where less amount of stock was planted.

\section{Discussion}

British Columbia's gene resource management (GRM) policy played a major in shaping the incremental seed deployment, whereas the spatial pattern of plantations was documented and tracked over time and space (British Columebia Ministry of Forests, Mines AND LANDS, 2010). As a result, between 1970 and 2004, seed selection focused on using the best genetic quality sources (i.e., orchard seed) capitalizing on advances made in several tree improvement programs (MORGENSTERN and WANG, 2001). This period can depict the policy's three historical stages, each representing a different stage of development. For example, the interior spruce tree improvement program is characterized by: 1) developmental stage during which the tree improvement program was first planned and initiated, 2) immature stage where breeding and testing resulted in the establishment of several seed orchards, and 3) mature stage with substantial orchard seed production of high genetic gain and diversity.

The British Columbia Forest Genetic Council strategically sets the target of genetically improved seed use (i.e., orchard class "A" seed) to reach $75 \%$ of the total reforestation program on BC crown land by 2013 (BRitish Columbia Ministry of Forests and RANGe, 2005). This triggered high demand for orchard seeds in 
multiple zones and species for two reasons; namely, class " $A$ " seed delivers relatively higher genetic gain and diversity than local wild populations (class "B" seed and natural regeneration) (STOEHR and EL-KASSABY, 1997), and high quality seed ensures better improvement of standing timber (BRITISH COLUMBIA MinistRY OF Forests AND RANGE, 2008). The variation of genetic resources development exists both temporally and spatially among different species. The Prince George SPZ had such rapid increase of class "A" seed use after 1995 due to the stable seed production from the seed orchards in the area (Woods, 2007). By 2001, the annual class "A" seed use in the Prince George SPZ exceeded the $75 \%$ set target (Figure 3) indicating that the availability of better genetic improvement has substantially affected the genetic composition of the reforestation material.

During the mature stage (1995-2004), plantation and management operations generated clusters of plantations from the same seed source in the Prince George SPZ (Figure 5). The hotspot of these clusters as in red color in Figure 4a, all using orchard \#214 seeds and this spot was located in the north of Prince George city (Figure 4a). However, the blue cool spots also formed 2 clusters (Figure 5) in the south and southwest of Prince George city with more plantation area but less deployment of \#214 seeds (Figure 4a). It is noteworthy to note that these hotspots are often located near roads indicative of the clustering nature of logging operations. These three clusters represented $20 \%$ of the total regeneration, covering only $0.6 \%$ of the total area of the Prince George SPZ. In other words, from 1970 to 2004, the plantation hotspot in the northwest of this SPZ was very frequently treated with class " $\mathrm{A}$ " seed from orchard \#214. Such high degree of clustering of class "A" seed might increase the potential risks for these planted trees. For example, if epidemics of diseases or pests have a suitable niche in these forests, their negative impacts are not easy avoided due to the high concentration of genetically similar improved forest stands planted in proximity to one another (WANG and KEMBALL, 2010). To mitigate such risks, using analyses such as this is prudent for designing a deployment strategy of a particular orchard's seed, thus buffering such uncertainty. MACCLEERY (1995) suggested that a mosaic pattern of tree stands tends to have a lower probability of the risks caused by fires or insect epidemics. Thus, the diversity of tree species and tree size is a factor of stand establishment that should be considered during regeneration (WANG and CHEN, 2010). In addition, an increased mixture of plantation and natural regeneration areas may serve to increase the genetic diversity of the forests (ELKASSABY et al., 2003). However, unpredictable factors such as changes in climatic conditions and/or pests need to be assessed when such clusters occur (PARKS and BEMIER, 2010).

Decades of spatial data records bookkeeping for the silviculture openings and seed use created a comprehensive updated data bank, and made the task of decision support easier and more advanced. Therefore, our assessment and tracking of seed use in Prince George SPZ was possible. However, not all zones or species had such high quality data as interior spruce, and more efforts to improve record keeping would help to ensure that this data can be used to enhance decision making specifically in light of changing environmental conditions.

It is imperative that every effort is made to continue to improve the quality of long-term record keeping in relation to gene resource management, although systems like the seed planning and registry application actively provides seed and vegetative lot information and queries (BRITISH COLUMBIA Ministry OF ForESTS AND RANGE, 2007b). One suggestion from our present study is developing a unique opening ID for the entire province that can be used as a key to join spatial and aspatial datasets. Currently, there are duplicates in the spatial dataset that are not attributable to multi-opening harvest areas and are due in part to the maintenance of separate data sets in various regions, presumably to speed up processing times. This makes the implementation of data integrity rules virtually impossible to enforce without central administration and regular quality assurance testing. Also, there continue to be non-spatial opening records without spatial references. While the occurrence of these odd records has indeed shrunk dramatically over the years to $1 \%$ of the total number of openings in 2004, there is still room for improvement.

The method presented is applicable across multiple zones and species in BC and with little effort when spatial and attribute historical records are available. Furthermore, it would efficiently guide and inform the notion of limits, and program goals for forestry policy and decision makers. With greater reliability of these types of metrics, effective population size, genetic worth, and other quantitative indicators could be used to streamline efforts to improve the management of the forest resources. The status reports related to genetic diversity and genetic gain could be split into smaller spatial levels such as Seed Planning Units or Seed Planning Zones to evaluate the overall state of forest improvement, since the current report is only at the provincial scale (BRITISH COLUMBIA MINISTRY OF Forests AND RANGE, 2007a, 2010).

Additionally, the present study provided a GIS-based approach to search for and identify plantations by seed orchard and seedlot over time and space. This in turn provides the needed sites proposed in EL-KASSABY and LSTIBUREK (2009) for the implementation of the "Breeding without Breeding" concept. These sites in fact could be considered as progeny tests planted under real conditions as opposed to those of "groomed" test sites established by tree improvement specialists. The information generated from DNA fingerprinted individuals could be related to the orchard's parental population and the pedigree of these individual trees could be reconstructed, generating a genealogical network resembling structured pedigree mating design for further quantitative genetic analyses-hence the term "Breeding without Breeding."

Furthermore, climate factors and tree performance variables can be introduced into the model to address issues of forest adaptation because of higher mortality 
rates (ALLEN et al., 2010). Since the interior spruce is predicated to lose its contemporary habitat due to the climate change in BC ((HAMANN and WANG, 2006), the climate-based analysis is critical for developing and assessing a sound gene resource management decisionsupport system.

\section{Conclusions}

In 1970, the British Columbia Forest Service established the records of silvicultural and reforestation activities, which facilitated the development of the present study. A GIS-based method was developed to track interior spruce seed deployment to assess the potential impacts of silviculture on the forest landscape. The result depicted three distinct periods of silvicultural history; namely, developing stage of tree improvement planning and execution (1970-1987), followed by immature phase for genetically improved seed deployment (1988-1994), and a mature stage where orchards became the dominant source for seed use (1995-2004). The spatial temporal monitoring identified several seed classes, orchard seeds ("A"), selected natural seeds ("B+"), as well as the non-select classes "B" (and "N" not labeled). There were significant gaps in selected seed use among these three stages; however, after 1987, orchard seeds played a key role in the reforestation. Orchard's seed use in the mature stage exceeded the provincial target of $75 \%$ in the Prince George SPZ. Orchard \#214 was the main producer of class "A" seed that was more frequently deployed in the Prince Georgelow unit or the SBS and ESSF BEC zones. Such high genetic quality of seed sources supports the gene resource management mission of achieving its sustainability goals with improved gain and resilience of reforestation.

A major outcome of this work is the visualization ability to compare different genetic classes distributed spatially and temporally, as well as assessing the presence of hotspots. By assessing the hotspots, this method is capable of identifying areas with potential risks of intensive clustering of plantations due to pathogen, pests or fires and demonstrating the spatial clusters of silviculture activities. This method could be also applied to different species in different Seed Planning Zones. Increasing the availability of climate and additional genetics data would facilitate extending the model's ability to support gene resource management decision making.

\section{Acknowledgments}

We would like to appreciate all the comments from the reviewers and editors. We would also thank J.S. Padolsky, H-D. Liang, S. Kuntz and Drs. A. HAMANN and X-L. WANG for comments and suggestions. Funds from the Johnson's Family Forest Biotechnology Endowment, British Columbia Forest Investment Account Forest Genetic Conservation and Management program, and Natural Sciences and Engineering Research Council of Canada- Discovery and IRC grants to YAK are highly appreciated.

\section{References}

Allen, C. D., A. K. Macalady, H. Chenchouni, D. Bachelet, N. McDowell, M. VennetieR, T. KitZBerger, A. Rigling, D. D. Breshears, E. H. Hogg, P. Gonzalez, R. Fensham, Z. Zhang, J. Castro, N. DemiDova, J. H. Lim, G. Allard, S. W. Running, A. SEmerci and N. CовB (2010): A global overview of drought and heat-induced tree mortality reveals emerging climate change risks for forests. Forest Ecology and Management 259: 660-684.

Anselin, L. (1995): Local Indicators of Spatial Association- - LISA. Geographical Analysis 27: 93-115 DOI 10.1111/j.1538-4632.1995.tb00338.x

British Columbia Ministry of Forests AND RANGe (2005): Tree improvement in British Columbia [online]. Available from http://www.fgcouncil.bc.ca/brochure-treeimprove-05.pdf [ accessed 18 December 2009].

British COLUmbia Ministry OF Forests AND RANGE (2007a): Indicator 6 - genetic diversity - the state of British Columbia's forests - 2006 [online]. Available from http://www.for.gov.bc.ca/hfp/sof/2006/06.htm [accessed 26 June 2008].

British COLUmbia Ministry of Forests AND RANGe (2007b): Seed planning and registry application [online]. (May 28 th 2008 , http://www.for.gov.bc.ca/HTI/ spar).

British Columbia Ministry of Forests AND RANGe (2008): Chief Forester's Standards for Seed Use. Victoria/B.C. [online]. Available from http://www.for.gov.bc.ca/code/ cfstandards/html/index.htm [accessed 25 January 2010].

British Columbia Ministry of Forests AND Range (2009a): Seed Planning Zones [online]. Available from http://www.for.gov.bc.ca/hti/seedp_zones/index.htm [accessed 25 January 2010].

British Columbia Ministry of Forests AND RANGe (2009b): Biogeoclimatic Ecosystem Classification/Plant Ecology [online]. Available from http://www.for. gov.bc.ca/HRE/ecoearth/Bioge.htm [accessed 25 January 2010].

British Columbia Ministry of Forests And Range (2010): The State of British Columbia's Forests, $3^{\text {rd }}$ ed. Forest Practices and Investment Branch, Victoria/ B.C. [online]. Available from www.for.gov.bc.ca/hfp/sof/index. htm\#2010_report [accessed 16 March 2011].

British Columbia Ministry og Forests, LANDS AND Naturtal Resource Operations (2011): Reporting Silviculture Updates and Landstatus Tracking System (RESULTS) [online]. Available from http://www.for.gov. bc.ca/his/results [accessed 16 March 2011].

GEOBC (2011): The Land and Resource Data Warehouse (LRDW), BRITISH Columbia Ministry og ForESTS, LANDS AND NATURTAL Resource Operations [online]. Available from http://geobc.gov.bc.ca [accessed 25 October 2011].

El-Kassaby, Y. A., B. G. Dunsworth and J. KRAKOwsKI (2003): Genetic evaluation of alternative silvicultural systems in coastal montane forests: western hemlock and amabilis fir. Theoretical and Applied Genetics 4: $598-610$.

El-Kassaby, Y. A. and M. LstibureK (2009): Breeding without breeding. Genetics Research 91: 111-120.

ESRI (2011): ArcGIS Desktop: Release 10. Environmental Systems Research Institute, Redlands/California. 
Forest Genetic Council of BRITISH Columbia (2009): Forest Genetics Council of British Columbia Strategic Plan 2009 - 2014 [online]. ISSN1710-3614. Available from http://www.fgcouncil.bc.ca/StratPlan0914-LayoutWeb-22Dec09.pdf [accessed 25 October 2011].

Hamann, A., M. P. Koshy, G. Namkoong and C. C. Ying (2000): Genotype x environment interactions in Alnus rubra: developing seed zones and seed-transfer guidelines with spatial statistics and GIS. Forest Ecology and Management 136: 107-119.

Hamann, A., P. Smets, A. D. Yanchuk and S. N. Aitken (2005): An ecogeographic framework for in situ conservation of forest trees in British Columbia. Canadian Journal of Forest Research 35: 2553-2561.

Hamann, A., S. N. AitKen and A. D. Yanchuk (2004): Cataloguing in situ protection of genetic resources for major commercial forest trees in British Columbia. Forest Ecology and Management 197: 295-305 DOI 10.1016/j.foreco.2004.05.020

HAmann, A. and T. WANG (2006): Potential effects of climate change on ecosystem and tree species distribution in British Columbia. Ecology 87: 2773-2786.

JENnINGs, M. D. (2000): Gap analysis: Concepts, methods, and recent results. Landscape Ecology 15: 5-20.

Kurz, W. A., C. C. Dymond, G. Stinson, G. J. Rampley, E. T. Neilson, A. L. Carroll, T. Ebata and L. SafranyiK (2008): Mountain pine beetle and forest carbon feedback to climate change. Nature 452: 987-990.

LEDIG, F. T. (1986): Conservation strategies for forest gene resources. Forest Ecology and Management 14: 77-90.

LEFÈVRE, F. (2004): Human impacts on forest genetic resources in the temperate zone: an updated review. Forest Ecology and Management 197: 257-271.

Lipow, S. R., K. VANCE-Borland, J. B. St ClaiR, J. HenDERSON and C. MCCAIN (2004): Gap Analysis of Conserved Genetic Resources for Forest Trees. Conservation Biology 2: 412-423.

MacCleery, D.W. (1995): The Way to a Healthy Future for National Forest Ecosystems in the West: What Role Can Silviculture and Prescribed Fire Play [online]? US forest services, Washington, D.C.. Available from http://www.fs.fed.us/rm/pubs_rm/rm_gtr267/rm_gtr267_ 037_045.pdf [accessed 19 January 2011].

MallaWAarachChI, T., P. Walker, M. Young, R. Smyth, H. LYNCH and G. DUDGEON (1996): GIS-based Integrated Modelling Systems for Natural Resource Management. Agricultural Systems 2: 169-189.

MEIDINGER, D., J. POJAR and S. MAH (2005): Biogeoclimatic ecosystem classification. In: Forestry Handbook for British Columbia. $5^{\text {th }}$ Edition. Edited by S. B. WATts and L. Tolland. The Forestry Undergraduate Society, Faculty of Forestry, University of B.C., Vancouver, B.C. pp. 48-119.

Mitchell, A. (2005): The ESRI Guide to GIS Analysis, Volume 2. ESRI Press, Redlands, California.

MoRgenstern, E. K. (1996): Geographic Variation in Forest Trees: Genetic Basis and Application of Knowledge in Silviculture. University of British Columbia Press, Vancouver, B.C. pp. 137-142.

Morgenstern, E. K. and B. S. P. WANG (2001): Trends in forest depletion, seed supply, and reforestation in Canada during the past four decades. Forestry Chronicle 77(6): 1014-1021.

Morin, X., C. Augspurger and I. Chuine (2007): Processbased modeling of species'distributions: what limits temperate tree species' range boundaries? Ecology 9: 2280-2291.
Nienstaedt, H., and J. C. ZAsada (1990): Picea glauca (Moench) Voss-White Spruce. In: Silvics of North America, Vol. 1, Conifers [online], edited by R. M. BuRNs and B. H. HonkALA. Available from http://www.na.fs.fed.us/ pubs/silvics_manual/table_of_contents.shtm [accessed 29 November 2009].

PARKs, C. G. and P. BerniER (2010): Adaptation of forests and forest management to changing climate with emphasis on forest health: a review of science, policies and practices. Forest Ecology and Management 259: 657-659.

PeArson, A. F. (2010): Natural and logging disturbances in the temperate rain forests of the Central Coast, British Columbia. Canadian Journal of Forest Research 40: $1970-1984$.

Pojar, J., K. Klinka and D.V. Meidinger (1987): Biogeoclimatic ecosystem classification in British Columbia. Forest Ecology and Management 22: 119-154.

Powell, M., A. ACCAD and A. SHAPCotT (2005): Geographic information system (GIS) predictions of past, present habitat distribution and areas for re-introduction of the endangered subtropical rainforest shrub Triunia robusta (Proteaceae) from south-east Queensland Australia. Biological Conservation 2: 165-175.

Silverman, B. W. (1986): Density Estimation for Statistics and Data Analysis. Chapman and Hall, New York. Pp. 76.

StOEHR, M. and Y.A. EL-Kassaby (1997): Levels of genetic diversity at different stages of the domestication cycle of interior spruce in British Columbia. Theoretical and Applied Genetics 94: 83-90.

Sara, R. L., K. Vance-Borland, J. B. St. Clair, J. HenDERSON and M. C. CINDY (2004): Contributed Papers Gap Analysis of Conserved Genetic Resources for Forest Trees. Conservation Biology 2: 412-423.

TREe Improvement BRANCH (2007): Forest tree gene resource management in british columbia. Tree Imrovement Branch, (Ed.). In: Tree Imrovement Branch Update Extention Note. Tree Imrovement Branch, Victoria, B.C.

Tree Improvement Branch (2009): Gene Resource Management [online]. Available from http://www.for.gov.bc. ca/hre/forgen [accessed 19 Feburary 2010].

Tsinrintzis, V. A., R. HAMid and H. R. Fuentes (1996): Use of Geographic Information Systems (GIS) in water resources: A review. Water Resources Management 4: 251-277.

WANG, S. and H. Y. H. CHEN (2010): Diversity of northern plantations peaks at intermediate management intensity. Forest Ecology and Management 259: 360-366.

WanG, G. G. and K. J. Kemball (2010): Effects of fire severity on early survival and growth of planted jack pine, black spruce and white spruce. Forestry Chronicle 86: 193-199.

Woods, J. H. (ed.) (2006): Forest Genetics Council of B.C. Business Plan 2006-2007 [online]. Available from http://www.llbc.leg.bc.ca/public/PubDocs/bcdocs/343629/ FGCBP_2006_07.pdf [accessed 25January 2010].

Woods, J. H. (ed.) (2007): Forest Genetics Council of B.C. Business Plan 2007-2008 [online]. Available from http://www.llbc.leg.bc.ca/public/PubDocs/bcdocs/343629/ FGCBP_2007_08.pdf [accessed 25 January 2010].

YING, C. C. and A. D. YANCHUK (2006): The development of British Columbia's tree seed transfer guidelines: Purpose, concept, methodology, and implementation. Forest Ecology and Management 227: 1-13. 